\title{
Determinants of Hyperemesis Gravidarum Among Pregnant Women in Public Hospitals of Mekelle City, North Ethiopia, 2019: Unmatched Case-Control Study
}

\author{
Zenebe Tefera ( $\nabla$ zenebe7834@gmail.com ) \\ Wollo University \\ Mandefro Assefaw \\ Wollo University \\ Mulugeta W/Selassie \\ Wollo University
}

\section{Research Article}

Keywords: Hyperemesis Gravidarum, Determinants, unmatched case-control study, Mekelle, Ethiopia

Posted Date: April 9th, 2021

DOl: https://doi.org/10.21203/rs.3.rs-366722/v1

License: (c) (i) This work is licensed under a Creative Commons Attribution 4.0 International License.

Read Full License 


\section{Abstract}

Background: Globally, hyperemesis gravidarum affects 0.3 to $3.6 \%$ of pregnant women. The etiology of hyperemesis gravidarum is unclear. In Ethiopia, limited studies have been conducted on the determinants of hyperemesis gravidarum. Therefore this study is aim to identify the determinants of hyperemesis gravidarum among pregnant women in public hospitals of Mekelle city, North Ethiopia.

Methods: An unmatched case-control study was conducted from May to October 2019, with the ratio of 1:2(109 cases and 218 controls). Cases were women with hyperemesis gravidarum and controls were women who had no hyperemesis gravidarum. Cases were enrolled using consecutive sampling techniques and controls were selected by a systematic random sampling technique. Data were collected by interview using a structured questionnaire and analyzed using SPSS version 22. Statistical significance was considered at $\mathrm{p}-0.05$, and the strength of association was assessed by odds ratio and $95 \%$ confidence intervals.

Result: Being housewife (AOR=2.43; 95\% Cl; 1.27, 4.62), unplanned pregnancy (AOR=2.58; 95\% Cl; 1.27 , 5.24), had family history of hyperemesis gravidarum ( $A O R=3.85 ; 95 \% \mathrm{Cl} ; 1.69,8.75)$. H. pylori infection $(A O R=3.50 ; 95 \% \mathrm{Cl} ; 1.92,6.39)$, high perceived stress (AOR=7.01; $95 \% \mathrm{Cl} ; 2.56,19.18)$ and being in the first and second trimester $(\mathrm{AOR}=6.01 ; 95 \% \mathrm{Cl} ; 1.87,19.26)$, and $(\mathrm{AOR}=4.73 ; 95 \% \mathrm{Cl} ; 1.59,14.00)$ were determinant of hyperemesis gravidarum.

Conclusion and Recommendations: In this study; being a housewife, unplanned pregnancy, had a family history of hyperemesis gravidarum, $\mathrm{H}$. pylori infection, high perceived stress, and being in the $1^{\text {st }}$ and $2^{\text {nd }}$ trimester of pregnancy were found to be the determinants of hyperemesis gravidarum. We recommend stress should be minimized through psychological support during follow up of pregnancy. Screening for $\mathrm{H}$. Pylori should be taken as routine investigations for pregnant women who complain of nausea and vomiting.

\section{Background}

Hyperemesis gravidarum $(\mathrm{HG})$ is a severe type of vomiting of pregnancy which has got deleterious effect on the health of the mother and/or incapacitates her in day-to-day activities (1). Its adverse effect includes dehydration, weight loss and starvation ketosis proved by positive ketone in urine at least once during pregnancy (1). This may result in fluid and electrolyte imbalance and affecting the nutritional status and is potentially lethal if left untreated $(2,3)$. Hyperemesis gravidarum was considered for a long time to be a disorder caused by psychological distress, fear of childbirth, or resentment of the pregnant state $(4,5)$. Globally, the prevalence of HG was found to be between 0.3 and $3.6 \%$ with an average of $1.1 \%$ (6). It's prevalence in Ethiopia also ranges from $4.4 \%$ to $8.2 \%(7-9)$.

Hyperemesis gravidarum is one of the health problems during pregnancy and it affects women's daily lives and was found to have adverse effects on daily life functioning. Clinical complications from nutritional deficiencies, psychological disorder, gastrointestinal trauma, and neurologic damage are the 
most common morbidities seen in women with $\mathrm{HG}(10,11)$. It also contributes to the termination of wanted pregnancies that affects the couple family planning. Women with $\mathrm{HG}$ often require hospitalization, as a result, they lose time to both paid employment and housework with a significant economic burden $(9,10,12)$. Hyperemesis gravidarum also increases the risk for adverse pregnancy outcomes such as low birth weight, preterm birth, small-for-gestational-age infants, and low APGAR score (13). It also hurts women's ability to care for their children, affects their relationship with partner and work capacity for most of the women (10).

The cause of $H G$ is unclear, but it is widely agreed that it is a multifactorial condition with sociodemographic, obstetrics, medical, and physiological contributing determinants $(12,14,15)$. However, a conflict between studies was found. Limited studies have been conducted to identify the determinants of hyperemesis gravidarum in Ethiopia moreover; no study is done in the Tigray region. Therefore, this study aimed to identify determinants of $\mathrm{HG}$, which could reduce the adverse perinatal outcome, hospitalization; time lost from paid employment, physical, psychological, economic, and social burdens of HG on women's lives, through prevention and early initiation of intervention

\section{Materials And Methods}

\section{Study area and period}

The study was conducted in public hospitals of Mekelle city namely Ayder, Mekelle, and Quiha hospital from May 1 to October 30, 2019. Mekelle is the capital city of Tigray regional state located $780 \mathrm{~km}$ from Addis Ababa the capital city of Ethiopia. These public hospitals are serving a population of 9 million from Tigray, Afar, and southeast Amhara. According to 2018, the hospital's health management information system reports; 5322 pregnant women had their first antenatal care follow up.

\section{Study design}

A facility-based unmatched case-control study design was employed.

\section{Population}

\section{Source population:}

The source population was all pregnant women who visited the maternity center of the study hospitals during the study period.

\section{Study population}


All pregnant women who were admitted to the hospitals with the diagnosis of hyperemesis gravidarum during the study period were study population for cases, whereas all pregnant women who visited the hospitals for antenatal care service during the study period were study population for controls.

\section{Inclusion and exclusion Criteria}

\section{Inclusion Criteria}

Pregnant women who were hospitalized due to HG diagnosed by the clinicians were included as cases and pregnant women who were visiting antenatal care services at the same time but not have symptoms of $H G$ were included as controls.

\section{Exclusion Criteria}

Pregnant women with severe nausea and vomiting, but diagnosed to have a concurrent medical and surgical illness (pyelonephritis, dyspepsia, and acute abdomen) were excluded.

\section{Sample size determination and sampling technique}

\section{Sample size determination}

The sample size was calculated with the assumption of a double population proportion formula for an unmatched case-control study using Epi Info software version 7.0. The following parameters were considered: $95 \%$ confidence interval, power was $80 \%$; control to case ratio was 2:1 and different sample sizes were produced from previously identified determinants of HG and the maximum and manageable sample size was obtained by taking perceived stress as a determinant factor from a previous study done in south Ethiopia; where the proportion of exposure among cases to be $17.7 \%$ and among controls $6.1 \%$ with an odds ratio of $3.3(16)$. This yields a maximum sample size of 296 (99 cases and 198 controls). By adding $10 \%$ non-response rate, the final sample size required for the study was 327 (109 cases and 218 controls).

\section{Sampling technique}

Cases were selected by a consecutive sampling technique with daily monitoring of all new admissions until the sample size was fulfilled. For each case, two controls were selected and this procedure was continued until the required sample size was attained. A systematic sampling technique was employed to select controls. 


\section{Study variables}

\section{Dependent variable}

Hyperemesis gravidarum

\section{Independent variables}

Sociodemographic variables:

- Age,

- Residence,

- Ethnicity,

- Marital status,

- Religion,

- Educational status and

- Occupational status

Obstetrics and gynecology related variables:

- Primigravida

- Nulliparous

- Molar pregnancy

- Multiple pregnancy

- Gestational age

- Unplanned pregnancy

- History of dysmenorrhea

- History of abortion and

- History of neonatal death

The medical and psychological related variable

- Helicobacter pylori infection

- History of diabetic Mellitus

- History of hyperemesis gravidarum

- Family history of hyperemesis gravidarum

- History of pre-pregnancy motion sickness

- History of depression 
- Perceived stress status

\section{Data collection procedure}

Data were collected through face-to-face interviews and chart reviews using structured and pretested questionnaires adapted from existing literature (14-16). The questionnaire includes four sections; sociodemographic, obstetric and gynecologic characteristics, medical and psychological characteristics, and questions that measured perceived stress status. The data were collected by five BSc midwives using the Tigrigna version questionnaire.

\section{Data quality control}

The questionnaire was prepared originally in English and was translated to Tigrigna (local language) and back to English by two independent persons to keep the consistency of the questionnaires. Data collectors and supervisors were trained. Close supervision was done by the principal investigator and supervisor during data collection. Completeness of the data was checked at the field level.

\section{Data analysis}

The collected data were checked for completeness and entered into Epi-data version 3.1. Then the data were exported to SPSS version 22 and cleaned, coded, and collapsed before subsequent analysis. Summary statistics such as median, mean, interquartile range, and standard deviation were computed for cases and control groups. The independent variables were cross-tabulated among cases and controls. Then bivariate analysis was carried out to assess the crude association between the independent and outcome variable. The variables with $p$-value $<0.05$ in bivariate analysis were entered into a multivariable logistic regression to assess the net effect by controlling confounders. The variables with $p<0.05$ in multivariable logistic regressions were considered as statistically significant determinants for HG. The adjusted odds ratio (AOR) with 95\% confidence interval (Cl) was used to assess the strength of association. As a result, the model used was good as indicated by the Omnibus model goodness of fit test ( $p 0.001$ with the cut point $<0.05)$ and Hosmer \& Lemeshow model goodness of fit test $(p=0.618$ with cut point $>0.05$ ). Multicollinearity test was done and all determinants had a variance inflation factor less than 10 indicating that there was no high correlation between the independent variable.

\section{Operational definition}

- Cases: Pregnant women who were hospitalized due to hyperemesis gravidarum diagnosed by the clinicians based on the clinical and laboratory finding. 
- Controls: Pregnant women who visited antenatal care services in the study facilities, but did not have symptoms of hyperemesis gravidarum.

- Perceived stress: It was measured with the perceived stress scale (PSS). PSS is a 10-item multiplechoice self-report psychological instrument for measuring the perception of stress. Each answer was scored 0 (never) to 4 (very often). Individual scores on the PSS can range from 0 to 40 with higher scores indicating higher perceived stress. Scores ranging from 0-13 would be considered low stress. Scores ranging from 14-26 would be considered moderate stress. Scores ranging from 27-40 would be considered high perceived stress (17).

\section{Ethical consideration}

All the methods carried under this study were approved by the Ethics and Research Committee of Mekelle University (ERC1444/2018). The anonymity and confidentiality of the women were maintained in accordance with current legislation. Written informed consent was obtained from all participants. A letter of cooperation was obtained from Tigray regional health bureau. Information on the study was explained to the participants, including the objective, procedure, and benefit of the study. The respondents were informed that they have the right to refuse or decline participation in the study at any time.

\section{Results}

\section{Maternal sociodemographic characteristics}

In this study, a total of 105 cases and 210 controls were successfully interviewed with a response rate of $96.3 \%$. The same proportion of cases (88.6\%) and controls (88.6\%) were in the age group of 20-34 years. The median age of case and control was $27(\mathrm{IQR}=5)$ and $28(\mathrm{IQR}=6)$ respectively. The majority of cases $(86.7 \%)$ and controls (93.8\%) were living in urban. The majority $(81.9 \%)$ of cases and $(79.0 \%)$ of controls were Orthodox. Eighty-six percent of cases and $95.2 \%$ of controls were married. About forty-six percent of cases and $25.2 \%$ of controls were housewives. (Table 1 )

Table 1: Sociodemographic characteristics of respondents in public hospitals of Mekelle City, North Ethiopia, 2019 


\section{Hyperemesis Gravidarum}

\section{Characteristics}

Cases $(n=105) \quad$ Controls $(n=210) \quad$ Total $(n=315)$

$N(\%)$
$N(\%)$
$\mathrm{N}(\%)$

Age of the mother(in years) $(n=315)$

$<20$

20-34

$35-49$

Residence $(n=315)$

Urban

Rural

Ethnicity $(n=315)$

Tigryan

Afar

Religion $(n=315)$

Orthodox

Muslim

Catholic

Protestant

Marital status $(n=315)$

Married

Single

Educational level( $(n=315)$

Illiterate

$<8$ grade

9-12grade

Diploma and above

Occupational status of the mother $(n=315)$
$3(2.9)$

93(88.6)

$9(8.6)$

91(86.7)

14(13.3)

103(98.1)

2(1.9)

86(81.9)

15(14.3)

1(0.9)

$3(2.9)$

90(85.7)

15(14.3)

200(95.2)

10(4.8)

7(3.3)

166(79.0)

37(17.6)

2(1.0)

5(2.4)
8(2.5)

288(91.4)

27(8.6)

306(97.1)

9(2.9)

252(80.0)

52(16.5)

3(1.0) 


\begin{tabular}{|llll|}
\hline Housewife & $48(45.7)$ & $53(25.2)$ & $101(32.1)$ \\
\hline Merchant & $12(11.4)$ & $27(12.9)$ & $39(12.4)$ \\
\hline Other $^{\text {b }}$ & $9(8.6)$ & $14(6.7)$ & $23(7.3)$ \\
\hline b = Farmer and student & & & \\
\hline
\end{tabular}

\section{Obstetrics and gynecological characteristics of respondents}

The proportion of multigravida among cases and controls was $69.5 \%$ and $81 \%$ respectively. Similarly, $63.8 \%$ of cases were para one and above. The median gestational age of the women for the case and control was $16(\mathrm{IQR}=8)$ and $18(\mathrm{IQR}=11)$ respectively. About 62.9 and 57.1 percent of cases and control were admitted during the second trimester respectively. About thirty-four percent of cases and $12.9 \%$ of controls reported that the current pregnancy was unplanned. Most of the pregnancy (96.2\%) among cases and $98.1 \%$ among controls were single tones. (Table 2 )

Table 2: Obstetrics and gynecological characteristics of respondents in public hospitals of Mekelle City, North Ethiopia, 2019 


\begin{tabular}{|c|c|c|c|}
\hline \multirow{3}{*}{ Characteristics } & \multicolumn{2}{|c|}{ Hyperemesis Gravidarum } & \multirow{3}{*}{$\begin{array}{l}\text { Total }(n=315) \\
N(\%)\end{array}$} \\
\hline & Cases $(n=105)$ & Controls $(n=210)$ & \\
\hline & $\mathbf{N}(\%)$ & $\mathbf{N}(\%)$ & \\
\hline \multicolumn{4}{|l|}{ Gravidity $(n=315)$} \\
\hline Primigravida & $32(30.5)$ & $40(19.0)$ & 72(22.9) \\
\hline Multigravida & $73(69.5)$ & $170(81.0$ & 243(77.1) \\
\hline \multicolumn{4}{|l|}{ Parity $(n=315)$} \\
\hline Nulliparous & $38(36.2$ & $47(22.4)$ & $85(27.0)$ \\
\hline Para one and above & $67(63.8)$ & 163(77.6) & $230(73.0)$ \\
\hline \multicolumn{4}{|l|}{ Unplanned pregnancy $(n=315)$} \\
\hline Yes & $36(34.3)$ & $27(12.9)$ & $63(20.0)$ \\
\hline No & $69(65.7)$ & 183(87.1) & 252(80.0) \\
\hline \multicolumn{4}{|c|}{ Abortion history/pregnancy loss before 28 weeks $(n=243)$} \\
\hline Yes & $7(9.6)$ & $11(6.5)$ & 18(7.4) \\
\hline No & $66(90.4)$ & 159(93.5) & 225(92.6) \\
\hline \multicolumn{4}{|l|}{ History of dysmenorrhea $(n=315)$} \\
\hline Yes & 12(11.4) & 18(8.6) & $30(9.5)$ \\
\hline No & $93(88.6)$ & 192(91.4) & 285(90.5) \\
\hline \multicolumn{4}{|c|}{ History of previous neonatal death $(n=230)$} \\
\hline Yes & $4(6.0)$ & $8(4.9)$ & $12(5.2)$ \\
\hline No & $63(94.0)$ & 155(95.1) & 218(94.8) \\
\hline \multicolumn{4}{|l|}{ Gestational age $(n=315)$} \\
\hline First trimester(0-12 week) & $34(32.40$ & $48(22.9)$ & $82(26.0)$ \\
\hline Second trimester (13-27 week) & $66(62.9)$ & $120(57.1)$ & $186(59.0)$ \\
\hline Third trimester (28-40 week) & $5(4.8)$ & $42(20)$. & $47(14.9)$ \\
\hline \multicolumn{4}{|l|}{ Number of embryo/fetus $(n=315)$} \\
\hline Singleton & $101(96.2)$ & 206(98.1) & $307(97.5)$ \\
\hline Multiple & $4(3.8)$ & $4(1.9)$ & $8(2.5)$ \\
\hline History of molar pregnancy $(n=315)$ & & & \\
\hline
\end{tabular}




\begin{tabular}{|llll|} 
Yes & $2(1.9)$ & $1(0.5)$ & $3(1.3)$ \\
No & $103(98.1)$ & $209(99.5)$ & $312(98.7)$ \\
\hline
\end{tabular}

\section{Medical and psychological characteristics of respondents}

Concerning medical characteristics, the proportion of history of diabetic mellitus among cases was $1.9 \%$ and that of controls was $1.0 \%$. Twenty percent of the cases and $9 \%$ of controls were reporting a history of HG in their mothers and sisters. About forty-six percent of cases and $21.4 \%$ of controls were seropositive for Helicobacter pylori (H. pylori) infection. Pre-pregnancy motion sickness was reported by $13.3 \%$ of cases and $10 \%$ of controls. According to the perceived stress scale, it was observed that $19 \%$ of cases and $9 \%$ of controls had high perceived stress (Table 3 ).

Table 3: Medical and psychological characteristics of respondents in the public hospitals of Mekelle City, North Ethiopia, 2019 


\section{Characteristics}

History of diabetic mellitus $(n=315)$

Yes
No
vidory of hyperemesis
vidarum(n=243)

gravidarum $(n=243)$

$\begin{array}{llll}\text { Yes } & 16(21.9) & 32(18.8) & 48(19.8) \\ \text { No } & 57(78.1) & 138(81.2) & 195(80.2)\end{array}$

Family history of hyperemesis gravidarum $(n=315)$

\begin{tabular}{llll} 
Yes & $21(20.0)$ & $19(9.0)$ & $40(12.7)$ \\
\hline No & $84(80.0)$ & $191(91.0)$ & $275(87.3)$
\end{tabular}

H. pylori immunoglobulin test result $(n=315)$

$\begin{array}{llll}\text { Positive } & 48(45.7) & 45(21.4) & 93(29.5) \\ \text { Negative } & 57(54.3) & 165(78.6) & 222(70.5)\end{array}$

History of pre-pregnancy motion sickness $(n=315)$

$\begin{array}{llll}\text { Yes } & 14(13.3) & 21(10.0) & 35(11.1) \\ \text { No } & 91(86.7) & 189(90.0) & 280(88.9)\end{array}$

History of depression $(n=315)$

\begin{tabular}{llll} 
Yes & $3(2.9)$ & $5(2.4)$ & $8(2.5)$ \\
\hline No & $102(97.1)$ & $205(97.6)$ & $307(97.5)$
\end{tabular}

Perceived stress status $(n=315)$

Low stress

26(24.8)

111(52.9)

137(43.5)

Moderate stress

$60(57.1)$

90(42.9)

150(47.6)

High perceived stress

19(18.1)

$9(4.3)$

28(8.9)

\section{Determinants of hyperemesis gravidarum}


The bivariate analyses revealed that marital status, residence, maternal occupation, gestational age, gravidity, parity, unplanned pregnancy, had a family history of $\mathrm{HG}$, Helicobacter pylori infection, and perceived stress were found to have an association with the development of hyperemesis gravidarum.

After controlling for potential confounds on multiple logistic regression analysis; being a housewife, unplanned pregnancy, being in the first and second trimester of pregnancy, family history of HG, H. pylori infection and perceived stress were identified as determinants of hyperemesis gravidarum among pregnant women.

Accordingly, housewives pregnant women were 2.43 times more likely to develop $\mathrm{HG}$ as compared to employed pregnant women ( $\mathrm{AOR}=2.43 ; 95 \% \mathrm{Cl} ; 1.27,4.62)$. In the same manner, women with unplanned pregnancy were 2.58 times more likely to develop $\mathrm{HG}$ as compared to women with planned pregnancy $(A O R=2.58 ; 95 \% \mathrm{Cl} ; 1.27,5.24)$. Similarly, women in the first and second trimester of pregnancy were 6.01 and 4.73 times at increased risk of developing $\mathrm{HG}$ as compared to women in the third trimester(AOR=6.01; 95\% Cl; 1.87, 19.26) and $(\mathrm{AOR}=4.73 ; 95 \% \mathrm{Cl} ; 1.59,14.00)$ respectively.

Pregnant women who had a family history of hyperemesis gravidarum were 3.85 times more likely to develop HG as compared to those who had no family history of $\mathrm{HG}(\mathrm{AOR}=3.85 ; 95 \% \mathrm{Cl} ; 1.69,8.75)$. Similarly, women who had $\mathrm{H}$. pylori infection were significantly at increased risk of having $\mathrm{HG}$ compared to women who were not infected ( $\mathrm{AOR}=3.50 ; 95 \% \mathrm{Cl} ; 1.92,6.39)$. In the same manner, pregnant women who had high perceived stress were 7.01 times more likely to develop HG as compared to women with low perceived stress (AOR=7.01; 95\% Cl; 2.56, 19.18) (Table 4)

Table 4: Determinants of hyperemesis gravidarum among pregnant women in public hospitals of Mekelle City, North Ethiopia, 2019 


\section{Hyperemesis Gravidarum}

Characteristics
Cases $(\mathrm{n}=\quad$ Controls $(\mathrm{n}=210)$

105)

(\%)
COR

$(95 \% \mathrm{Cl})$

Residence $(n=315)$

Urban

91(86.7)

197(93.8)

0.43(0.19, $0.95)$

Rural

$14(13.3) \quad 13(6.2)$

1

1

Marital status $(n=315)$

Married

90(85.7) 200(95.2)

1

1

Single

$15(14.3) \quad 10(4.8)$

$3.33(1.44$
$7.71)$

$2.37(.79,7.11)$

Occupational status $(n=315)$

Employed

Housewife

Merchant

Other ${ }^{b}$

36(34.3) 116(55.2)

48(45.7) 53(25.2)

12(11.4) 27(12.9)

14(6.7)

$1 \quad 1$

2.92(1.69, 2.43(1.27, 5.01) 4.62)*

$1.43(.66, \quad .73(.27,1.97)$

3.11)

$2.07(.83, \quad 1.16(.37,3.58)$

Gravidity $(n=315)$

Primigravida $32(30.5) \quad 40(19.0)$

1.86(1.09,

$1.31(.32,5.38)$

3.19)

Multigravida

73(69.5)

$170(81.0$

1 1

Parity $(n=315)$

Nulliparous

$38(36.2 \quad 47(22.4)$

1.97(1.18, 3.29)

Para one and

67(63.8) 163(77.6)

1 1

above

Unplanned pregnancy

$(n=315)$

Yes

$36(34.3) \quad 27(12.9)$

3.54(1.99,

$6.26)$

2.58 (1.27,

No

69(65.7) 183(87.1)

1 
Gestational age

$(n=315)$

\begin{tabular}{|c|c|c|c|c|}
\hline First trimester & $34(32.40$ & $48(22.9)$ & $\begin{array}{l}5.95(2.13 \\
16.60)\end{array}$ & $\begin{array}{l}\text { 6.01(1.87, } \\
19.26)^{\star}\end{array}$ \\
\hline Second trimester & $66(62.9)$ & $120(57.1)$ & $\begin{array}{l}\text { 4.62(1.74, } \\
12.24)\end{array}$ & $\begin{array}{l}4.73(1.59 \\
14.00)^{\star}\end{array}$ \\
\hline Third trimester & $5(4.8)$ & $42(20)$. & 1 & 1 \\
\hline \multicolumn{5}{|c|}{ Family history of hyperemesis gravidarum $(n=315)$} \\
\hline Yes & $21(20.0)$ & 19(9.0) & $\begin{array}{l}2.51(1.28, \\
4.92)\end{array}$ & $\begin{array}{l}3.85(1.69 \\
8.75)^{\star \star}\end{array}$ \\
\hline No & $84(80.0)$ & 191(91.0) & 1 & 1 \\
\hline \multicolumn{5}{|c|}{ H. pylori immunoglobulin test result(n=315) } \\
\hline Positive & $48(45.7)$ & $45(21.4)$ & $\begin{array}{l}3.09(1.86 \\
5.12)\end{array}$ & $\begin{array}{l}3.50(1.92 \\
6.39) \star \star\end{array}$ \\
\hline Negative & $57(54.3)$ & 165(78.6) & 1 & 1 \\
\hline \multicolumn{5}{|c|}{ Perceived stress status(n=315) } \\
\hline Low stress & $26(24.8)$ & $111(52.9)$ & 1 & 1 \\
\hline Moderate stress & $60(57.1)$ & $90(42.9)$ & $2.85(1.66,4.87)$ & $\begin{array}{l}2.01(1.07 \\
3.79)^{\star}\end{array}$ \\
\hline High stress & 19(18.1) & $9(4.3)$ & $9.01(3.66,22.19)$ & $7.01(2.56,19.18)^{\star \star}$ \\
\hline
\end{tabular}

\section{Discussion}

The current study investigates the determinates of hyperemesis gravidarum among pregnant women in public hospitals of Mekelle City and the finding shows that being a housewife was significantly associated with the development of hyperemesis gravidarum as compared to employed women. This finding is supported by a study conducted in the Bale zone, southern Ethiopia, and Netherland $(15,18)$.

This study also shows that unplanned pregnancy was significantly associated with hyperemesis gravidarum as compared to a planned pregnancy. The possible explanation for the observed association could be that pregnant women may perceive the negative effect of unplanned pregnancy on their job, education, income, relationship with their partner and motivation to achieve their goal, which may expose them to anxiety and tension, which could lead them to be at the more severe end of nausea and vomiting. However, this finding contradicts a study done in southern Ethiopia in which no association was seen between HG and unplanned pregnancy (15). The reason may be due to the difference in the study area and sample size. However, the finding is consistent with a study conducted in Turkey (19). 
A family history of hyperemesis gravidarum was also found to have a significant association with HG. This finding contradicts a study conducted in Bale zone, south Ethiopia in which no association was seen between HG and family history of hyperemesis gravidarum (15). The possible reason for the difference could be that the family history of hyperemesis gravidarum was based on self-report, which may lead to misclassification. However, this finding is consistent with a study conducted in Norway which shows that women with hyperemesis were at significantly higher risk of developing hyperemesis in their own pregnancy compared with daughters of women without hyperemesis (20). This finding also consistent with a study conducted in the USA which shows that a significantly higher risk of hyperemesis in women whose sisters or mothers had the disorder (21). The possible explanation for the observed association could be due to either shared environmental determinants among families or inheritance of some factors that can contribute to the development of hyperemesis gravidarum.

Women in the first and second trimester of pregnancy were significantly more likely to suffer from HG than those women who were in the third trimester of pregnancy. The finding is consistent with a study conducted in Jimma University Medical Center (southwest Ethiopia) and Bale zone (south Ethiopia) and the University of Michigan(United States) $(7,15,22)$. However, the finding contradicts a study conducted in Turkey, which shows that gestational age had no significant association with HG (23). This may be due to the difference in sample size in which the sample size used in Turkey was half of the sample size of the current study.

Similarly, H. pylori infection was found to have a significant association with hyperemesis gravidarum. This finding is consistent with a study conducted in Addis Ababa (Ethiopia), Egypt, and China (24-26). This may be due to that $\mathrm{H}$. pylori may aggravate the hormone-induced changes in the chemoreceptor trigger zone in the brain stem including the vomiting center and electric functioning of the stomach, which could lead an infected pregnant woman to develop severe nausea and vomiting (27). However, the finding is in contradicts a study conducted in Europe (28). This might be explained by the difference in socioeconomic status between the two study areas in which the prevalence rate of H. Pylori-infection is much higher in women with low socioeconomic status (29). Pregnant women with moderate and high perceived stress were found to have a statistically significant association with hyperemesis gravidarum as compared to women who have no low stress. This finding is consistent with a study done in south Ethiopia, Egypt, Turkey, and the USA $(15,22,29,30)$.

\section{Conclusion}

This study concludes that being a housewife, being in the first and second trimester of pregnancy, unplanned pregnancy, had a family history of hyperemesis gravidarum, Helicobacter pylori infection, and high perceived stress were found to be the determinants of hyperemesis gravidarum among pregnant women. We recommend that health promotion messages are needed to focus to improve the utilization of contraceptives methods to prevent unplanned pregnancy and screening for $\mathrm{H}$. Pylori should be taken as routine investigations for pregnant women who complain of nausea and vomiting. Healthcare 
providers should look for the emotional stress during pregnancy and should minimize the stresses through psychological support during follow up.

\section{Declarations}

\section{Acknowledgements}

We would like to express our appreciation to Mekelle University for funding this study and the study participants for their valuable time and cooperation, as well as data collectors and supervisors for their commitment throughout the data collection process.

\section{Authors' contributions}

ZT: This author was involved in proposal write up, data collection, analysis and interpretation, literature review, writing up of the first and subsequent draft of the manuscript. MA: This author helped in data collection, analysis and interpretation and writing up of the manuscript. MW: This author critically reviewed the manuscript. All authors have read and approved the manuscript.

\section{Funding}

The study was funded by Mekelle University

\section{Availability of data and materials}

The datasets generated and analyzed during the study are available from the corresponding author upon request. All relevant data are within the manuscript and its supporting information files.

\section{Ethics approval and consent to participate}

All the methods carried under this study were approved by the Ethics and Research Committee of Mekelle University (ERC1444/2018). The anonymity and confidentiality of the women were maintained in accordance with current legislation. Written informed consent was obtained from all participants.

\section{Consent for publication}

Not applicable.

\section{Competing interests}

The authors declare that there are no conflicts of interest regarding the publication of this article.

\section{Author details}

1. Department of Midwifery, College of Medicine and Health Sciences, Wollo University, Dessie, Ethiopia, 2. Department of Pediatrics and Child Health Nursing, College of Medicine and Health Sciences, 
Wollo University, Dessie, Ethiopia

\section{References}

1. D.C Dutta KH. Hyperemesis gravidarum. Eighth Edi. DC Duttas Textbook of Obstetrics. 2015. 181$182 \mathrm{p}$.

2. Gabra A, Habib H, Gabra M. Hyperemesis Gravidarum, Diagnosis, and Pathogenesis. Crit Care Obstet Gynecol. 2019;05(01):1-5.

3. Fossum S, Vikanes V, Næss, Vos L, et al. Hyperemesis gravidarum and long-term mortality. BJOG An Int J Obstet Gynaecol. 2016;124(7):1080-7.

4. Gallos I, Farren J, Tobias A, et al. Psychological morbidity associated with hyperemesis gravidarum: a systematic review and meta-analysis. An Int J Obstet Gynaecol. 2017;12(4):20-30.

5. Poursharif B, Korst LM, Fejzo MS, et al. The psychosocial burden of hyperemesis gravidarum. J Perinatol. 2012;28:176-81.

6. Castillo MJ, Phillippi JC. Hyperemesis gravidarum: A holistic overview and approach to clinical assessment and management. J Perinat Neonatal Nurs. 2015;29(1):12-22.

7. Hailemariam S, Dereje A HJ. Prevalence of Hyperemesis Gravidarum and Associated Factors Among Pregnant Women at Jimma University South West Ethiopia: EC Gynaecol. 2016;5(3):376-87.

8. Kejela G, Getu S, Gebretsdik T. Prevalence of Hyperemesis Gravidarum and Associated Factors in Arba Minch Southern Ethiopia. Clin Mother Child Heal. 2018;15(1):1-5.

9. Kuma T, Yusuf L, Negash S. Assessment of nausea and vomiting of pregnancy on antenatal clients of Addis Ababa. Ethiop J Heal Dev. 2013;27(3):200-7.

10. Heitmann K, Nordeng H, Havnen GC. The burden of nausea and vomiting during pregnancy: BMC Pregnancy Childbirth. 2017;17(1):75.

11. London V, Grube S, Sherer DM, et al. Hyperemesis Gravidarum: A Review of Recent Literature. 2017;11203:161-71.

12. Mullin P, Ching C SF. Risk factors, treatments, and outcomes associated with prolonged hyperemesis gravidarum. J Matern Fetal Neonatal Med. 2013;25(6):632-6.

13. Lutomski JE, Greene RA. Hyperemesis gravidarum: current perspectives. 2014;719-25.

14. Mahmoud GA, Sc DN. Prevalence and Risk Factors of Hyperemesis Graviderum Among Egyptian Pregnant Woman at the Woman 's Health Center. www.medicaljournalofcairouniversity.com. 2012;80(2):161-8.

15. Gonie Mekonnen A, Amogne FK. Risk Factors of Hyperemesis Gravidarum among Pregnant Women in Bale Zone Hospitals, Ethiopia. Clin Mother Child Heal. 2018;15(3):3-7.

16. Tan PC, Zaidi SN, Azmi N, et al. Depression, Anxiety, Stress and Hyperemesis Gravidarum : Temporal and Case Controlled Correlates. 2014;9(3):4-6.

17. Cohen, S., Kamarck, T., and Mermelstein R. Perceived Stress Scale (PSS). 1983. p. 24, 386-96. 
18. Roseboom TJ, Ravelli AC. maternal characterstics largely explayen poor pregnancy outcome after hyperemesis gravidarum. 2011;156(1):56-9.

19. Dr. Ayşe Nur AKSOY, Department of Obstetrics and Gynecology, Nenehatun Hospital, Erzurum T. Hyperemesis Incidence in Planned versus Unplanned Pregnancy. BMJ. 2013;23(6):72-4.

20. Grjibovski AM, Gunnes N, Vangen S, et al. Recurrence of hyperemesis gravidarum across generations: population based cohort study ${ }^{\circ}$. BMJ. 2006;340:1-5.

21. Zhang Y, Cantor RM, Macgibbon K, et al. Familial aggregation of hyperemesis gravidarum. YMOB. 2011;204(3):230.e1-230.e7.

22. Sharp BR, Sharp KM, Patterson B, et al. Treatment of Nausea and Vomiting in Pregnancy: Factors Associated with ED Revisits. West J Emerg Med. 2016;17(5):585-90.

23. Aksoy H, Aksoy Ü, Karadağ Öi. Depression levels in patients with hyperemesis gravidarum: a prospective case-control study. Springerplus. 2015;4(1):2-7.

24. Assefa Y. Association of Helicobacter pylori infection and hyperemesis gravidarum women. Matern abd child Heal. 2017;3(2):20-1.

25. Lingling L, Xiaoying Z, Shuping X HG. Helicobacter pylori Infection Is Associated with an Increased Risk of Hyperemesis Gravidarum. Hindawi. 2015;2015:13.

26. Mohaddesi H, Bahadori F. Comparison of Helicobacter pylori infection between pregnant women with hyperemesis gravidarumand and controls. Life Sci J. 2015;9(4):1315-7.

27. Sumona Saha M. NIH Public Access Nausea and Vomiting of Pregnancy. Gastroenterol Clin North Am. 2013;40(2):1-27.

28. Zhou X, Xiao S, Zhang G, et al. Helicobacter pylori Infection Is Associated with an Increased Risk of Hyperemesis Gravidarum: A Meta-Analysis. 2015;9-10.

29. Gabra A. iMedPub Journals Risk Factors of Hyperemesis Gravidarum: Review Article Abstract Introduction Risk Factors. 2018;12(6):1-5.

30. Yavuz Ş, Önder Ç, Ercan Y AK. Assessment of anxiety and depression levels of pregnant women with hyperemesis gravidarum in a case-control study. Arch Womens Ment Heal. 2012;4(1):32-6. 